Ciência eNatura, Santa Maria, v. 37 Part 1 2015, p. 71-74

\title{
Microwave Irradiation Assisted Synthesis 4-Hydroxy
}

\section{3-Iodobenzylguanidine(HIBG)}

\author{
M.Poursharifi ${ }^{*}-$ S.Shahi $^{2}$ \\ 1-Department of Chemistry management,Tehran science and research branch Islamic Azad \\ University \\ *M.Poursharifi@srbiau.ac.ir \\ 2- Department of Chemistry, Faculty of science, University of Guilan, Rasht, Iran
}

\begin{abstract}
Meta-iodo benzyl guanidine(MIBG) is an analogue of Noradernalin transmitter. When radiolabelled with 123 I and 131 , used for scan and diagnosis Adernal's tumor. Labeled MIBG with 131 I used in therapy of Neuroblastoma, Pheochromocytoma, Carcinoidsyndome and Neuroendocrine tumors. In our continuing efforts to develop MIBG analogues with higher therapeutic efficacy, we recently evaluated the structure-activity characteristics of several analogues of MIBG. We are interested in developing HIBG analogues containing hydroxyl at the 4-postion oF HIBG.generous of the some groups to activate the aromatic ring of a drug towards electrophilic radiodiodination may have merit. The resistance of HIBG to in vivo radiodiodination and amenability to kit production make it a strong candidate for clinical evaluation as a pheochromocytoma and neuroblastoma localzing agent. Microwave assisted heating under controlled conditions has been shown to be an invaluable technology for organic chemistry and during discovery applications since it often rise yield and dramatically reduce reaction times, typically form days or hours to minutes or even seconds.

Microwave Irradiation Assisted Synthesis of HIBG is started to produce 4-methoxybenzylamine. 4-methoxybenzylamine and hydriodic acid are mixed and heated for this purpose. Then under MBR condition 4-Hydroxybenzyl guanidine in sulphate form is prepared with additional Cyanamide and Sulphuric acid. After that Iodination is preformed under MBR condition and 4-Hydroxy-3-iodobenzyl guanidine sulphate formed, that can labeled with 131 and exchange to labeled 4-Hydroxy-3-iodobenzyl guanidine sulphate.
\end{abstract}

Keywords: Radiolabelling- MIBG- HIBG- Neuroblastoma- Pheochromocytoma- Carrcinoidsyndome- Microwave Batch Reactor 


\section{Introduction}

$\mathrm{n}$ recent years, Synthesis and labeling of MIBG analogues which are used in scan and diagnosis of adrenal tumors have become highly important. In this research, synthesis of HIBG is examined microwave irradiation assisted that resulted in higher therapeutic effect of HIBG compared to MIBG, plus a faster synthesis and higher efficiency when microwave irradiation assisted than thermal method.<smiles>COc1ccc(CN)cc1C=Cc1ccc(O)cc1</smiles>

Schema. 1

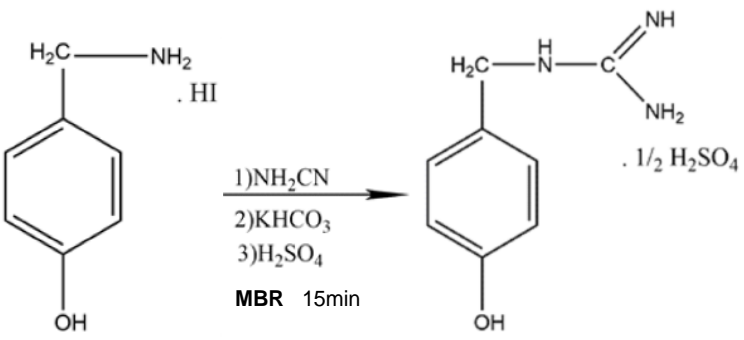

Schema.2

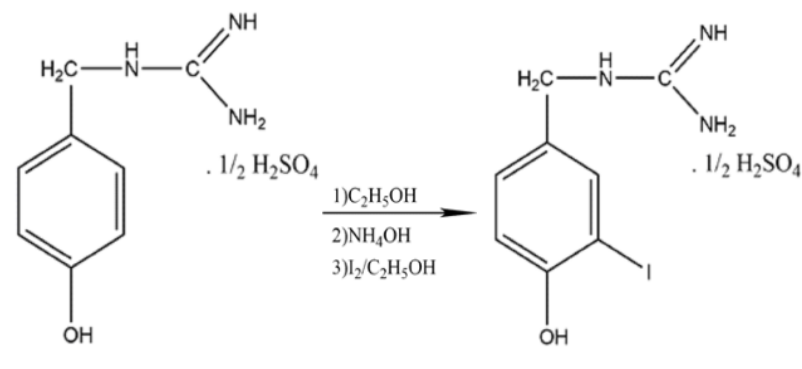

Schema.3

\section{EXPERIMENTAL METHOD}

Chloramine-T , 4-methoxybenzylamin , sodium iodide, hydriodic acid and Cyanamide were provided in the laboratory microwave from laboratory resources. Proton magnetic resonance (HNMR) and infrared spectrum (IR) of them were obtained.

\subsection{TASK PROCEDURE}

\subsubsection{4-Hydroxybenzylamin hydroiodide}

4-methoxybenzylamine $(125 \mathrm{mg}$, $1 \mathrm{mmol})$ was MBR irradiation assisted for $20 \mathrm{~min}$ with hydriodic acid(184mg, 3mmol)(German Merck). methyliode $\left(\mathrm{bp}: 30^{\circ} \mathrm{C}\right)$ was vacuum evaporated and extra $\mathrm{HI}$ was isolated with appropriate solvents (methyl acetate, acetic acid)after 3 times of recrystallization. needle crystals of 4hydroxybenzylaminhydriodide were appeared .(88\% yield) (Shema. 1$)$

m.p: $182^{\circ} \mathrm{C}$

$\operatorname{IR}(\mathrm{KBr}) \quad \mathrm{V}_{\max } \mathrm{c}^{\mathrm{cm}-1}: \quad 3400(\mathrm{OH}), \quad 3161.25(\mathrm{NH})$, 3006.77(NH),3000(sp² C-H, Arom)

\subsubsection{4-Hydroxybenzylguanidine sulphate}

4-Hydroxybenzylamin hydroiodide (502mg , 2mmol) and Cyanamide $(252 \mathrm{mg}, 0.6 \mathrm{mmol})$ were irradiation at $150^{\circ} \mathrm{C}$ for 15 minutes then they were cool to ambient temperature. The Remaining was solved in boiling water. Dissolved $\mathrm{KHCO}_{3}(220 \mathrm{mg}, 2.2 \mathrm{mmol})$ in $2 \mathrm{ml}$ of water, was added to the solution. The resulting solution was boiled for 2 minutes then was left to be cool to ambient temperature. Filtrated product of bicarbonate salt made in $4 \mathrm{ml}$ hot water as a suspension. Added $\mathrm{H}_{2} \mathrm{SO}_{4}(2 \mathrm{~N})$ drop by drop until $\mathrm{pH}$ became 2 . It boiled to become dense to $1 \mathrm{ml}$, then were cool. Colorless solid filtrated . it was recrystallized once more with water to achieve sulphat solid as a colorless crystal.(380mg , 90\% ) (Shema.2)

m.p: $260-262^{\circ} \mathrm{C}$

HNMR(300 MHZ ,MeOH)ठ: 7.11(d,2H ， $\mathrm{J}=8 \mathrm{HZ}), 6.74(\mathrm{~d}, 2 \mathrm{H}, \mathrm{J}=8 \mathrm{HZ}), 4.25(\mathrm{~S}, 2 \mathrm{H})$ 
2.2.3 4-hydroxy-3-idobenzylguanidine sulphate

Dissolved 4-Hydroxybenzylguanidine sulphate $(225 \mathrm{mg}, 1.05 \mathrm{mmol})$ in $\mathrm{EtOH}(30 \%$, $15 \mathrm{ml})$ and dense ammoniac solution and added a solution of $\mathrm{I}_{2}(199.9 \mathrm{mg}, 0.788 \mathrm{mmol})$ in $\mathrm{EtOH}(15 \mathrm{ml})$ in $0{ }^{\circ} \mathrm{C}$ were mixed. Once more in ambient temperature mixed for 18hours. In vacuum, solvent evaporated and the rest was recrystallized three times with water solvent to achieve (149mg , $82 \%$ ) (Shema.3)

m.p:208-210 ${ }^{\circ} \mathrm{C}$

HNMR(300MHz , MeOD)ঠ:6.76-7.65(m , 6H , $\left.\mathrm{ArH}, \mathrm{NH}_{2}\right), 4.10\left(\mathrm{~S}, 2 \mathrm{H}, \mathrm{CH}_{2}\right)$

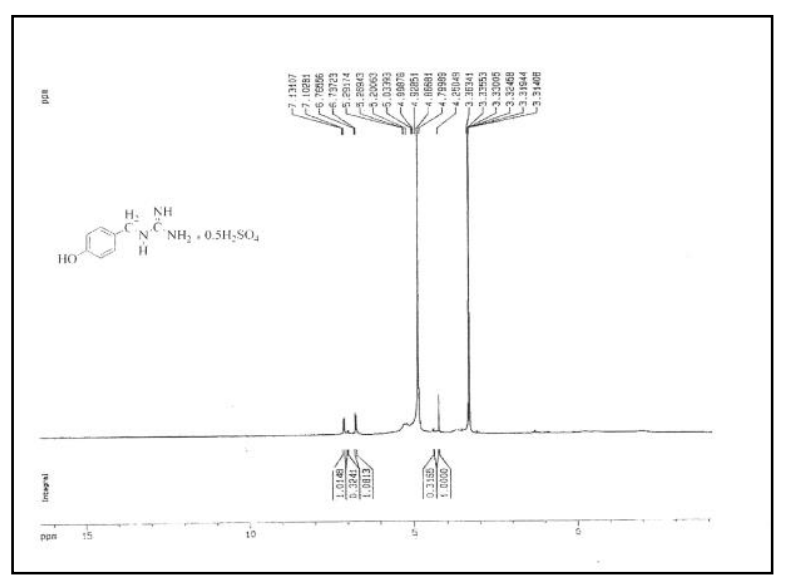

Figure1:HNMR of 4-Hydroxybenzylguanidine sulphate

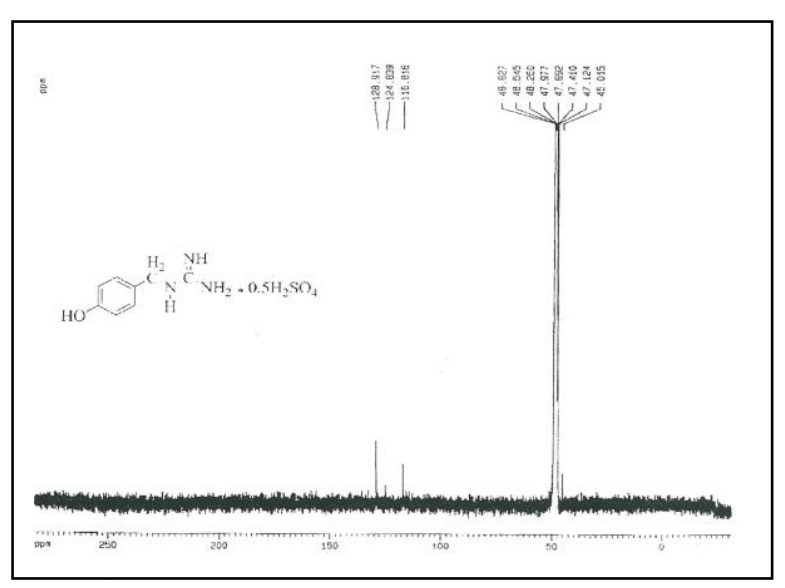

Figure2:CNMR of 4-Hydroxybenzylguanidine sulphate

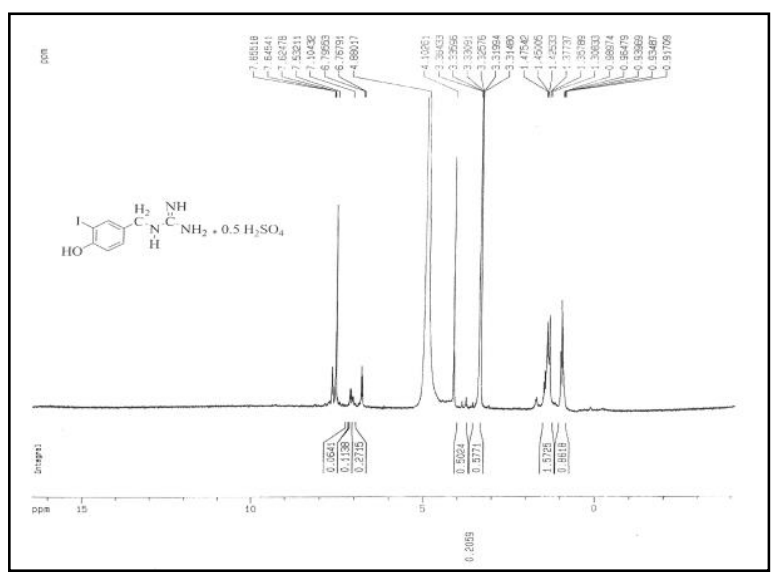

Figure3:HNMR of 4-hydroxy-3-idobenzyl guanidine sulphate

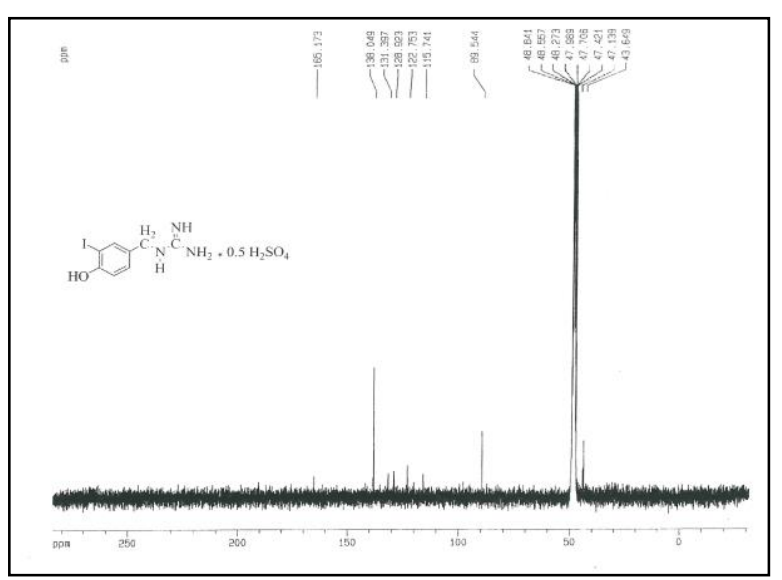

Figure4:CNMR of 4-hydroxy-3-idobenzyl guanidine sulphate

\section{RESULT DISSCUSION}

4-hydroxy-3-idobenzyl guanidine sulphate labeled easily with carrier added and nocarrier added structures. In addition, containing hydroxyl group in para-position, radiation iodo stabled in 3-position . this function reduce large amount of releasing scatter iodin in drug. 4-hydroxybenzyl guanidine sulphate (HBG) is an intermediate that has the ability to be labeled in the clinics by provided kit production. The far hospitals from central nuclear may have merit. Microwave irradiation assisted synthesis reduce reaction time with rise yield. 


\section{REFRENCES}

1.H.Salehi, M.Poursharifi , M.Rezaei, M.Gourani , 12th Annal Iranian Coungress on Necleur Medicene. 25.28,2008

2.Helen Lee, Muthiah N.Inbasekaran, et al:Development of kit-form analogs of metaiodobenzylguanidine. I Nucl Med 27:256267,1986

3.G.Vaidyanathan, D.J.Affeck, M.R.Zalutsky . No -carrier-added synthesis of a 4-methyl substituted meta-iodobenzylguanidine analogue.

4.G.Vaidyanathan, D.J.Affeck, M.R.Zalutsky : (4Fluoro-3-iodobenzylguanidine) , a potential MIBG analogue for positron Emission Tomography .J.Med . Chem. 37,3655-3662, 1994

5.G.Vaidyanathan, D.J.Affeck , M.R. Zalutsky: synthesis of king-and side chain-substituted meta-iodobenzylguanidine analogue. Bioconjugate chem 2001,19,786-797

6.Ganesan Vaidyanathen, Sriram Shsnkar, : meta-iodobenzylguanidine donna J. Affeck, et al derivatives containing asecond guanidine moiety. Elsevier Bioorg and Med Chem , 12:16491656, 2004

7.Radiopharmaceuicals in Nuclear Pharmacy and Nuclear Medicine. Second Edition, Ed By R.J.Kowalsky and S W Falen 2004. Pg 310314,713-716

8.Knickmeier, M, Matheja, P., et .al. clinical evaluation of no-carier m-iodobenzylguanidine for myocardial scintgrraphy. EJNM 2000; No.3.,302-307

9.T. Yassine, M. A. Bakir, S..Shanan, M. ALAsaad: Preparation, purification and quality control of 131 I-m-iodobenzylguanidine. J RAD Nucl Chem, 285,3,635-637,2003

10.G. Prabhakar , Kiran S. Mehra , N. Ramamoorthy, et al :Evaluation of radioiodination of meta-iodobenzylguanidine
(MIBG) catalyzed by in situ generated $\mathrm{Cu}(\mathrm{I})$ and directly added $\mathrm{Cu}(\mathrm{II})$. Pergamon Rad and Iso. 50,1011-1014, 1999

11. Inbasekaran M, Sherman PS, Brown LE, et al: Development of kit-form analogs of metaiodobenzylguanidine. J Nucl Med 24:P117 , 1983 (a bstr)

12. Inbasekaran $\mathrm{M}$, Lee $\mathrm{H}$, Wieland DM, et al : Radiopharmaceuticals Selective for Adrenergic Nevers , $186^{\text {th }}$ American Chemical Society National Meeting, Washington, DC , Aug. 28Sept.2,1983

13.Sisson JC,Frager MS,Valk TW,et al: Scintirgraphic localization of pheochromocytoma .N Engl J Med 305:12-17 